\title{
Dentists' Role in Diagnosis and Management of Oral Involvement of Nasopharyngeal Carcinoma: Serial Case Report
}

\author{
Theodorus H. Kadrianto ${ }^{1}$, Harum S. Noegroho ${ }^{2}$ \\ ${ }^{1}$ Oral Medicine Residency Program, Faculty of Dentistry, Universitas Indonesia, Jakarta 10430, Indonesia \\ ${ }^{2}$ Department of Oral Medicine, Faculty of Dentistry, Universitas Indonesia, Jakarta 10430, Indonesia \\ Correspondence e-mail to: theodorus.hedwin@yahoo.com
}

\begin{abstract}
Nasopharyngeal carcinoma (NPC) is still a significant health problem due to its relatively high incidence. Rarely, NPC could extend and involve the oral cavity, and may present as an ulceration or exophytic mass. Objectives: To discuss the rare clinical appearance of NPC involving the oral cavity and the significant role of dentists in its diagnosis and management. Case Report: We reported 3 cases of NPC with oral cavity involvement. In the first two cases, the patients presented with persistent oral ulceration with bone exposure and perforation to the above structure. The third patient presented with an ulcerated exophytic mass with temporomandibular disorder. The ulceration occurred due to bone destruction by the expansion of NPC mass, which indicated advance stage of the disease. All patients were managed with twice a day $0.2 \%$ chlorhexidine gluconate rinsing in combination with placing a chlorhexidine-moistened gauze to inhibit bacterial overgrowth and prevent secondary infection. The use of chlorhexidine was substituted by saline solution during patients' radiotherapy and chemotherapy cycles. Conclusion: Dentist's awareness to recognize the oral cavity involvement of NPC as well as recognizing the symptoms of NPC is very important, in order to make appropriate diagnosis and oral management. The oral management will eventually affect treatment outcome and quality of life.
\end{abstract}

Key words: exophytic mass, nasopharyngeal carcinoma, oral involvement, ulceration.

\section{INTRODUCTION}

Nasopharyngeal carcinoma (NPC) is still a significant health problem for the world today, especially Southeast Asian countries, due to its relatively high incidence. The highest incidence was in Southern China with $30-50$ per 100.000 . This type of cancer is the fourth highest in Indonesia, after cervical, breast, and skin cancer, while it also accounts for approximately $60 \%$ of all head and neck cancer cases in this country. For years, the national hospital in Indonesia had treated more than 100 NPC patients annually.,

The clinical proximity of nasopharynx to the oral cavity makes dentists actively involved before, during, and after the treatment of NPC. It may present first to the dental profession as facial pain, neck masses, difficulty in speech and swallowing, or temporomandibular disorders. ${ }^{3}$ In some rare cases, nasopharyngeal carcinoma may involve oral cavity and present as ulceration or exophytic mass. ${ }^{4}$ Dentists then must be aware of this possibility and put in mind all clinical features of nasopharyngeal carcinoma to ensure the appropriate diagnosis and management. This case series aims to discuss the rare clinical appearance of nasopharyngeal carcinoma involving the oral cavity and the significant role of dentists in its diagnosis and management.

\section{CASE 1}

A 56-year-old female referred from Department of ENT (Ear Nose Throat) with a diagnosis of nonkeratinizing undifferentiated NPC, with stage T3 N0 M0. She had been diagnosed with the same condition 14 years before. 

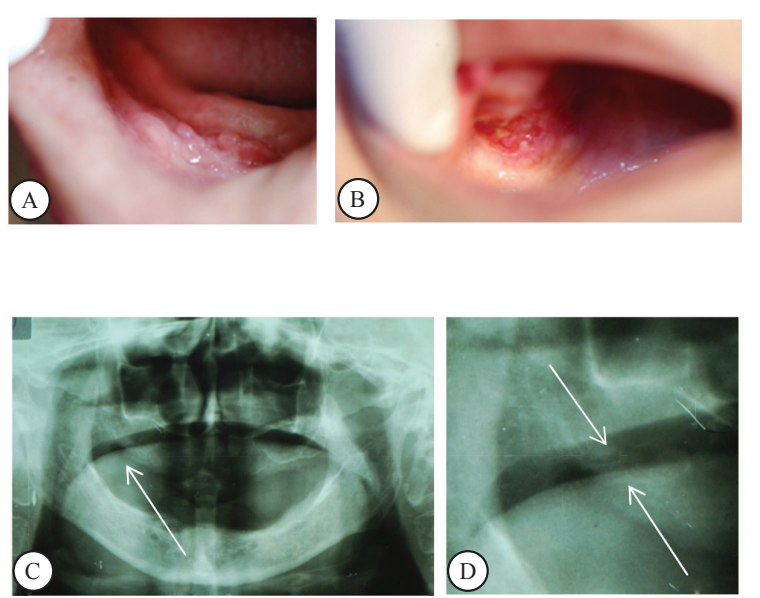

Figure 1. Clinical and radiographical features of the first case. A: Denture fissuratum on lower mucobuccal fold; B: Oral ulceration with bone exposure and necrotic surface on right posterior upper alveolar ridge; C: Loss of continuity on the right maxillary alveolar bone (arrow), D: Loss of continuity on the inferior wall of maxillary antrum (arrow)

She had done more than 30 cycles of radiotherapy for her first NPC. Her chief complaint was burning sensation on her anterior tongue, besides a continuous dull pain mixed with numbness on the right side of chin and lips throughout the day. Other complaints were right side nasal obstruction, nosebleeds, also fullness and pain in her right ear. She had lost four kgs, since her initial complaint one year before diagnosis.

Cervical neck mass could not be observed visually at the clinical examination, but then revealed on palpation at the right side of the neck. Intraoral examination showed edentulous alveolar ridge with an improper full denture, resulting in denture fissuratum on upper and lower anterior mucobuccal fold (Figure 1A). The mouth was dry with very little amount of saliva. An ulcer with bone exposure was found on the right posterior upper alveolar ridge, with a size of $1.5 \times 1.0$ $\mathrm{cm}$, and necrotic surface that bled easily (Figure 1B). The patient had never realized the ulcer before, nor experience pain and any other complaint regarding the ulcer. Orthopantomogram of the patient showed loss of continuity on the right upper posterior alveolar bone and in the inferior wall of the right maxillary sinus (Figure 1C and 1D).

CT-scan expertise from the radiologist explained that the NPC mass had destructed posteromedial wall of right maxillary sinus, the right medial pterygoid plate, posterior hard palate, and also infiltrated the soft palate. Discussion with internist also supported the diagnosis of the ulcer that was extension of NPC involving the oral cavity. The biopsy was not undertaken due to the clarity of clinical diagnosis among the clinician team.
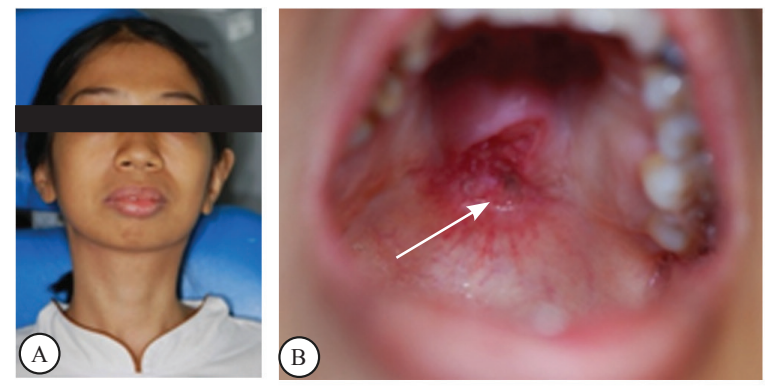

Figure 2. Clinical features of patient in case 2. A: No obvious cervical mass was detected visually; B: Ulceration in the midline of hard palate, with area of perforation detected clinically (arrow)

We instructed the patient to place small gauze moistened with $0.2 \%$ chlorhexidine gluconate on the ulcer $1-2$ minutes twice a day. Its use should be discontinued at the start of radiotherapy or chemotherapy, substituted by rinsing with saline solution. The patient was followed until she finished eight cycles of chemotherapy and 36 cycles of radiotherapy. The ulcer was still present with the same size and shape on clinical examination three months after the end of therapy. Dry mouth was managed by oral gel containing xylitol, colostrum, lactoperoxidase, lactoferrin, and lysozyme with satisfactory result. Improper denture was rebased before therapy.

\section{CASE 2}

A 30-year-old female was referred from the ENT department with diagnosis of nonkeratinizing undifferentiated NPC on staging. Initial complaint was nasal obstruction that was happend 1 year before diagnosis, followed by occurrence of neck mass on the left side. Other complaints included nosebleeds, headache on the left side, double vision on the left eye, and $11 \mathrm{kgs}$ weight loss. Oral complaint included toothache on left lower arch, blood on spitting, dry mouth, and painful "hole feeling" in the roof of the mouth. The patient reported occasional water burst out from the nose when rinsing or drinking.

Clinical examination showed 2 lobes of cervical mass on the left side of the neck, and 1 lobe on the right side, without any obvious large cervical mass detected visually (Figure 2A). Intraoral examination showed ulceration in hard palate measuring $1.5 \times 1.3 \mathrm{~cm}$ with perforated area with diameter of $3 \mathrm{~mm}$ within the ulcer (Figure 2B). Other findings included dry and desquamated lips, traumatic ulceration on lower labial mucosa, and poor oral hygiene.

The same instruction was given to this patient, to place small gauze moistened with $0.2 \%$ chlorhexidine 


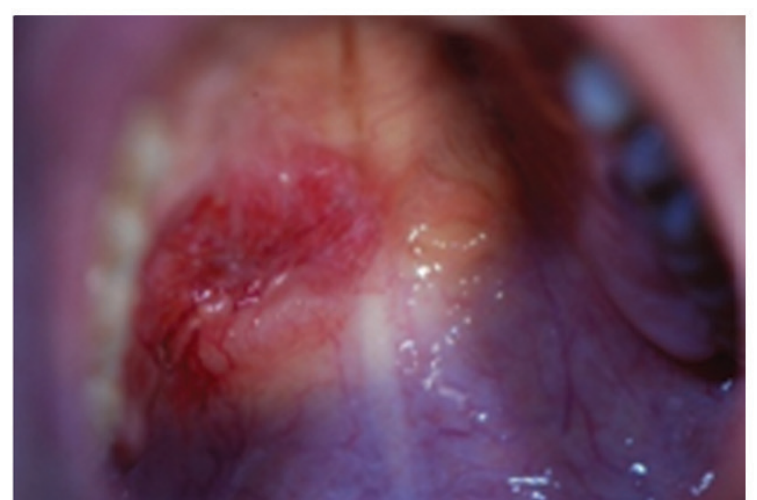

Figure 3. Clinical feature of patient in case 3 showed ulcerated exophytic mass on the right side of the palate

gluconate on the ulcer 1-2 minutes twice a day. Oral hygiene education was given to the patient, beside dental treatment planning such as scaling, extraction of non-restorable teeth, and some fillings. Unfortunately, the patient decided not to continue the therapy due to financial problem, despite available health insurance from the government. Staging of NPC could not be completed since CT-scan had not been done yet.

\section{CASE 3}

A 40-year-old male was referred from Department of ENT with diagnosis of nonkeratinizing undifferentiated NPC, with stage T4 N2 M0. Early complaint 3 years before was blood mixed with phlegm, followed with nosebleeds. These complaints was firstly misdiagnosed as nasal inflammation. When his right eye suffered from blurred vision, ophthalmologist also missed NPC as the main problem. His complaints at the time of oral examination was numbness and burning sensation at the nose and right side of the face, and also right side headache with stabbing and pulsating pain. Turning the head to the left side was difficult for him. He lost $13 \mathrm{kgs}$ of body weight in 1 year. The patient also felt changed upper and lower jaw usual relation, making it uncomfortable to bite. He felt his left teeth contacted first before the right teeth. Another oral complaint was mouth sore since 1 month before the examination without any pain, at the right side of the roof the mouth, and also dry mouth.

Cervical mass was palpable on the left side of the neck, without any significant neck enlargement seen visually. Intraoral examination showed an ulcerated exophytic mass with diameter of $2 \mathrm{~cm}$, rough surface, irregularly shaped with sharp edge on one side and diffuse border on another side, at the right side of hard palate, close to upper right molars extended to the midline (Figure 3). CT-Scan expertise from the radiologist showed that the NPC mass had extended to right parapharyngeal space, invaded right masticatory space, destructed medial and lateral posterior wall of right maxillary sinus and filled it. Oral hygiene was poor with calculus and caries on several teeth. The patient was asked to do oral rinsing with $0.2 \%$ chlorhexidine gluconate twice a day and to finish dental treatment prior to radiotherapy.

\section{DISCUSSION}

Nasopharyngeal carcinoma occurs in the epithelial lining of the nasopharynx. ${ }^{5}$ The nasopharyngeal region is connected to some important anatomical sites which resulted in specific clinical manifestations. It is situated posterior to the nasal cavity, just below the cranial base, above the upper surface of the soft palate, and in the middle of left and right eustachian tube ostium. The lateral pharyngeal recess behind the ostium or fossa of Rosenmuller remain the most common site for initial occurrence of nasopharyngeal carcinoma.,

Symptoms of nasopharyngeal carcinoma varied from one or more from four categories related with its anatomical site. The categories consist of (1) presence of tumor mass in the nasopharynx, manifested as epistaxis, nasal obstruction, and discharge; (2) dysfunction of the eustachian tube, associated with lateroposterior extension of the tumor to the paranasopharyngeal space, manifested as tinnitus, deafness, and otalgia; (3) erosion of the cranial base and palsy of the fifth and sixth cranial nerves, associated with the superior extension of the tumor, manifested as headache, diplopia, facial pain, and numbness; (4) neck masses which usually appear first in the upper neck, as frequently become the main reason for patients seeking medical treatment in Indonesia. ${ }^{2,5}$

Retrospective analysis conducted by Lee et al (1997) on 4768 patients of nasopharyngeal carcinoma showed symptoms presented at examination as neck mass $(76 \%)$, nasal dysfunction (discharge, bleeding, obstruction - 73\%), aural dysfunction (tinnitus, impairment of hearing - 62\%), headache (35\%), diplopia $(11 \%)$, facial numbness $(8 \%)$, weight loss $(7 \%)$, and trismus (3\%). The physical signs presented at the time of diagnosis were enlarged neck node $(75 \%)$ which represents metastasis, and cranial nerve palsy (20\%) which also represents a poor prognostic sign, both indicating an advance stage. The cranial nerves most frequently involved were the fifth $(12.5 \%)$ and the sixth $(10.5 \%)$ cranial nerve. ${ }^{3,7}$ According to the $7^{\text {th }}$ edition of the Union for International Cancer Control (UICC), the current staging of the invasion of tumor to bony structures of skull base and/or paranasal sinuses is considered as T3 (stage III), while involvement of cranial nerves is considered as T4 (stage IV). ${ }^{8}$ Delay in diagnosis and treatment will surely lower prognosis and survival rate. The other oral and non-oral symptoms that were found in our cases were presented in Table 1. 
Table 1. Non-oral and oral symptoms found in the three cases

\begin{tabular}{cll}
\hline Case & Non-Oral Symptoms & Oral Symptoms \\
\hline 1 & $\begin{array}{l}\text { Nasal obstruction, } \\
\text { epistaxis, otalgia, facial } \\
\text { pain and numbness, }\end{array}$ & $\begin{array}{l}\text { Burning sensation in } \\
\text { tongue, dry mouth }\end{array}$ \\
& $\begin{array}{l}\text { weight loss } \\
\text { Nasal obstruction, } \\
\text { epistaxis, headache, } \\
\text { diplopia, neck mass, } \\
\text { weight loss }\end{array}$ & $\begin{array}{l}\text { Toothache on left lower } \\
\text { arch, blood on spitting, } \\
\text { dry mouth, and painful } \\
\text { "hole" in the roof of the } \\
\text { mouth }\end{array}$ \\
& $\begin{array}{l}\text { Epistaxis, headache, } \\
\text { diplopia, facial pain and } \\
\text { numbness, weight loss }\end{array}$ & $\begin{array}{l}\text { Temporomandibular } \\
\text { disorder (changed bite } \\
\text { relation), mouth sore, dry } \\
\text { mouth }\end{array}$ \\
\hline
\end{tabular}

The non-oral symptoms found in our cases were consistent with usual findings in the literature. Burning sensation of the tongue and regional toothache in the first two cases were related with trigeminal nerve palsy, which could be categorized as common finding in nasopharyngeal carcinoma. Cranial nerve palsy was observed in all three cases, indicating all three patients had reached the advance stage of NPC. ${ }^{3,9}$ Dry mouth was mostly due to mouth breathing, compensating nasal obstruction that make the patients difficult to breathe normally, except in the first case which caused mainly by radiotherapy for the previous nasopharyngeal carcinoma.

Denture fissuratum that occurred in the first patient was not listed in Table 1, since it was not correlated with NPC mass, but more to improper denture on continuously changing edentulous alveolar ridge. However, NPC mass could also alter speech and fit of a denture, as it expands intraorally and affects the movement of soft palate, opening of the mandible, or integrity of nasopharyngeal seal, which did not happen in the first case. ${ }^{3}$

Temporomandibular disorder (TMD) is also commonly seen in cases of nasopharyngeal carcinoma, with symptoms such as joint clicking, pain during chewing, and limited jaw opening. Clinicians have to be aware that some of TMD and NPC symptoms are overlapping, such as facial pain, limited or deviated jaw opening, earaches and headaches. In fact, some NPC cases had been initially misdiagnosed as TMD, because of the subtleness of early signs and symptoms of NPC, which sometimes even unnoticed by the patient. It should be kept in mind that presence of TMD symptoms accompanied with any aural, nasal, or cranial nerve palsy symptoms must be investigated further by qualified medical professional. ${ }^{3,9}$

In our third case, TMD in the right side was consistent with the CT-Scan result, which indicating lateral spread to the right parapharyngeal space, continued by invasion to the masticatory space on the same side.
Masticatory space is bounded by a superficial layer of deep cervical fascia, which consists of muscles of mastication, ramus of the mandible, and the mandibular division of trigeminal nerve. Interference to the temporomandibular joint on that side resulting in acute malocclusion that characterized by heavy posterior contact on the ipsilateral side..$^{10,11}$

Oral cavity involvement of NPC is still rarely published and discussed in various NPC literature. Soft palate asymmetry is the most reported oral involvement, and considered as an early stage of NPC clinical manifestation. A study from the magnetic resonance of 308 patients from Pamela Youde Nethersole Eastern Hospital Hong Kong showed soft palate involvement in $21 \%$ of cases. Its superior surface forms the floor of the nasopharynx, which make NPC mass easily extend to the soft palate. Defective mobility of the soft palate was due to extension of tumor to the levator veli palatini muscle., ${ }^{9,12,13}$

Other kinds of oral cavity involvement such us oral ulceration or mass was very rarely published. In all patients, we found an oral lesion that suspiciously related to the NPC mass. The first two patients had an ulcer in their upper jaw, specifically the right posterior alveolar mucosa for the first patient and the midline of the hard palate for the second. The third one was ulcerated exophytic mass on the right side of the hard palate which extended to the midline.

In the first patient, CT-scan expertise showed that NPC mass had destructed the posteromedial wall of the right maxillary sinus, right medial pterygoid plate, posterior hard palate, and also infiltrated the soft palate. Anatomically, the right side of posterior alveolar mucosa was just beneath the posteroinferior wall of the right maxillary sinus. Orthopantomogram of the patient showed a loss of continuity on the right upper posterior alveolar bone below the maxillary sinus, manifested clinically as a ulceration with bony exposure. Oroantral communication was not clinically identified, but radiographically there was radiolucency in the inferior wall of the right maxillary sinus, connecting NPC mass to the alveolar bone defect through the eroded bone. This finding supported that this ulceration was part of the whole NPC mass.

Another possible diagnosis for the condition is osteonecrosis of the jaw (ONJ), that was defined as maxillary or mandibular exposed bone of any size that clinically appeared necrotic, without regard to duration or cause. ${ }^{14}$ Ulceration in our case is fit to this definition, but not to other definition which excluded patient who had exposed to radiation therapy to the head and neck. ${ }^{15,16}$ Since our patient already had done radiotherapy 14 years before, then osteoradionecrosis (ORN) came into consideration. The osteoradionecrosis was defined as slow-healing radiation-induced ischemic necrosis of bone with associated soft tissue necrosis of variable extent, occurring in the absence of local 
primary tumor necrosis, recurrence, or metastasis. ${ }^{17}$ Since the recurrent tumor could occur in very close proximity to the site of ulceration, then our case was excluded from this definition. Difference and controversy regarding definition of ONJ also made this clinical condition could not confidently diagnosed as ONJ.

The ulceration was not changed clinically on evaluation 3 months after all series of radiotherapy and chemotherapy. Healing process of ulceration with underlying bone defect in this case must be different with other relatively fast-healing soft tissue ulcerations. Radiation therapy induces tissue damage and death, as a result of destruction of epithelial, dermal, and endothelial cells lining small blood vessels. ${ }^{18,19}$ The condition results in ischemia, edema, inflammation, and then delayed fibrosis, which produces a hypovascular, hypocellular, and hypoxic state in the jawbone and the surrounding soft tissue, reducing normal wound healing capacity. Age is another important factor, as older patients have more medical problems and general deterioration in their ability to heal..$^{18,20}$

However, a study showed that bone regeneration could take place in previously destructed site of the bone due to NPC mass. The computed tomography imaging from 90 patients were analyzed, and bone regeneration was identified in 57 patients (63\%) 1 year after completing treatment of NPC. Bone regeneration was defined as recalcification or sclerotic change with partial or complete healing in the previous osteolytic bony defect. It was significantly correlates with treatment response and local control. ${ }^{21}$ In this case, bone regeneration was still too early to be evaluated. ${ }^{21}$

In the second case, there was ulceration in the midline of hard palate. Anatomically, the upper surface of the bone of hard palate forms the floor of the nasal cavity. ${ }^{13}$ This time, we could detect clinically small perforation within the ulcer which result in connection to the nasal cavity. The patient history also confirmed oro-nasal communication when water came out from the nose while rinsing and drinking. Other symptoms that included nasal obstruction and epistaxis confirmed that the NPC mass had extended to the nasal cavity.

Palatal ulcer with perforation to the nasal cavity could also be resulted from several conditions, such as infection (tertiary syphilis, chronic tuberculosis, or deep fungal infection), Wegener's granulomatosis, sarcoidosis, other neoplasms (salivary gland origin, squamous cell carcinoma, nasal NK/T-Cell lymphoma), and rare cause such as intranasal cocaine use. ${ }^{22-24}$ Oral medicine practitioner should be aware of the symptoms of these conditions and take a comprehensive history taking to make the right diagnosis and approach.

In these first two cases, oral ulceration was occurred due to bone destruction by the expansion of NPC mass.
Erosion of bones and paranasal sinuses is one of the indicators of tumor invasion, beside intracranial spread, infiltration of cranial nerves, and extension to more distant structures such as infratemporal fossa, orbit, or hypopharynx. The same study to 308 patients in Hong Kong as described earlier in this text showed maxillary antrum bony erosion in $4 \%$ of cases, as seen in our first case. Other bony erosion were clivus (41\%), sphenoid bone (38\%), pterygoid plate (27\%), petrous bone (19\%), ethmoid sinus $(6 \%)$, jugular foramen $(4 \%)$, pituitary fossa $(3 \%)$, and nasal septum (3\%). Intracranial spread of NPC mass could also occur through eroded bone. ${ }^{12}$ These could explain the spread of NPC mass in our cases.

In the third case, there was ulcerated exophytic mass in the hard palate. In this case, the identification of clinically any bone exposure nor perforation to sinus or nasal cavity found in the previous cases could not be established. Nevertheless, it was thought that the palatal mass was part of the NPC, possibly with the similar mechanism with the first two cases. Interpretation of the CT-scan revealed that NPC mass had destructed medial and lateral posterior wall of right maxillary sinus and filled the sinus with the tumour mass. This finding gave strong indication that the NPC mass could spread to the oral cavity through bone erosion. The close proximity between hard palate and maxillary sinus possibly made the way for tumour invation.

The presence of a palatal mass could also be a diagnostic problem for clinicians because there are several conditions which can manifested as palatal mass, such as palatal abscess, benign and malignant salivary gland neoplasms, benign neural tumors, and the traumatic or irritation fibroma. These lesions have many similar characteristics and may appear clinically indistinguishable. Comprehensive history taking should be directed to differentiate those possibilities, including symptoms of NPC. ${ }^{25}$ Since the patient was referred from ENT Department with established diagnosis of NPC, then we did not find any difficulty to diagnose the palatal mass.

Oral ulcerative conditions are always prone to secondary infection. Diverse oral microbiota with more than 700 bacterial species and wide range of species of viruses and yeasts, has great potential for secondary or opportunistic infection. ${ }^{26,27}$ One of the goals in management of oral ulceration will then always address the prevention of secondary infection, mainly with antiseptic mouthwash beside maintaining optimal oral hygiene. ${ }^{28,29}$ In patients undergoing chemotherapy or radiotherapy, decreased salivary flow rate will result in significant immunoprotein deficit, which then followed by pronounce increase in microorganisms. ${ }^{30}$ Oral ulceration then could be the portal of entry for microorganisms to invade the bloodstream, resulting in septicemia. Measures of prevention then should be done more vigorously in such condition. ${ }^{4,31,32}$ 
All of the three cases were managed with chlorhexidine gluconate, either with placing a small gauze on the ulcer, or by rinsing, depend on the site and size of the ulceration and also improvement of oral hygiene practice. Chlorhexidine gluconate is the most recommended regimen for any oral bone-exposed ulceration which easily facilitate bacterial overgrowth and secondary infection, because of its wide spectrum of activity encompassing gram-positive and gramnegative bacteria, yeasts, dermatophytes, and even some lipophilic viruses. ${ }^{15,33}$ It has strong antibacterial effects by altering the integrity of bacterial cell membrane, increasing its permeability, resulting in cell lysis and death. ${ }^{33}$ Chlorhexidine gluconate is also used to reduce the development of dental plaque and prevent the growth of cariogenic flora causing dental caries prior to the radiation therapy.,34

However, it should be emphasized to all patients that chlorhexidine use should be discontinued during radiotherapy and chemotherapy. The astringency property of chlorhexidince could cause detrimental effects such as pain and irritation in cases of radiationinduced mucositis, so that it is not recommended for prevention or treatment of oral mucositis in adults..$^{35,36}$

Education to maintain optimal oral hygiene should be given thoroughly to all patients to ensure maximum protection from secondary infection throughout cancer therapy. Subsequently the patients were sent to finish the pre-radiation dental treatment such as scaling, filling, and extraction of non-restorable teeth. These are routine procedures should be done for every patients who will undergo radiotherapy or chemotherapy, to minimize oral complications during or after therapy. 3,4

Once the patient starts the cancer therapy, careful attention should be given on the diagnosis and management of possible side effects on the oral cavity, beside maintenance of oral hygiene. One of the most significant problem is oral mucositis, which can be very painful and can significantly affect nutritional intake, mouth care, and quality of life. Infections associated with the oral mucositis lesions can cause life-threatening systemic sepsis during periods of significant immunouppression. ${ }^{31}$ Severity of oral mucositis could be minimized by identification and control of its risk factors. Patient-related risk factors includes age, gender, oral hygiene, presence of sharp teeth, salivary flow, nutritional status, presence of other systemic diseases or infections, bad habit, cancer type, and immunologic status, while therapy-related risk factors includes chemotherapeutic agent, field of radiation and fractionation, dosage and frequency of radiotherapy, and other medication. ${ }^{37}$ Other side effects of cancer therapy are salivary gland dysfunction, taste alteration, infection, and muscular fibrosis. ${ }^{36}$

Saline solution is one of the simplest recommended regimen for mouth rinse during radiotherapy or chemotherapy. ${ }^{32,36}$ The $0.9 \%$ sodium chloride usually used for infusion is the best composition, for stronger concentration may harm mucosal tissue. Alternatively, the patient can be asked to make it themselves, by adding approximately half teaspoon (approximately $2.5 \mathrm{~g}$ ) of table salt to $250 \mathrm{~mL}$ of water, but it should be prepared fresh at least once daily. The patient should rinse and swish approximately 1 tablespoon $(15 \mathrm{~mL})$, then expectorate. This can be repeated as often as necessary to maintain oral comfort. Saline solution can enhance oral lubrication directly as well as by stimulating salivary glands to increase salivary flow. Rinsing itself helps to maintain the moisture in the mouth, removes the remaining debris, and reduces the accumulation of plaque and infections. ${ }^{36}$

In cases of oral cavity involvement of NPC, the role of dentists should be more active, in maintaining the ulceration from the risk of secondary infection or other serious complications that will affect treatment outcomes, diet, and quality of life of the patients. ${ }^{4}$

\section{CONCLUSION}

In rare cases, nasopharyngeal carcinoma could extend and involve the oral cavity, and may present as an ulceration or exophytic mass, usually in advance stage of NPC. Although it is more likely for dentists to take care of patient referred from the ENT department with established diagnosis of NPC, they have to be aware of the symptoms of NPC to make the appropriate diagnosis and management, especially in the absence of obvious large cervical mass. Careful attention should be given in maintaining the ulceration from the risk of secondary infection or other serious complications. Dentists have significant role before, during, and after the treatment of NPC, especially in cases of oral cavity involvement.

\section{ACKNOWLEDGMENT}

Appreciation to Drs. Anandina Irmagita, Indriasti Indah Wardhany, Endah Ayu Triwahyuni and Sri Tjahjani Hanifa who involved in the management of three patients reported above. The patient's hospital fee was funded by the Ministry of Health Republic of Indonesia. 


\section{REFERENCES}

1. Yurnadi, Suryandari DA, Soeharso P, Moeloek N, Susworo R. Pola distribusi alotip gen Polymeric Immunoglobulin Receptor (PIGR) pada penderita karsinoma nasofaring (KNF) di Indonesia. Maj Kedokt Indon. 2010;60:489-95. Indonesian.

2. Roezin A, Syafril A. Karsinoma nasofaring. In: Soepardi EA, Iskandar N. Buku Ajar Ilmu Kesehatan: Telinga, Hidung, Tenggorok, Kepala, dan Leher, 5th ed. Jakarta: Balai Penerbit FK UI. 2001. p.146-50. Indonesian.

3. Mackie AM, Epstein JB, Wu JSY, StevensonMoore P. Nasopharyngeal carcinoma: the role of the dentist in assessment, early diagnosis and care before and after cancer therapy. Oral Oncol. 2000;36:397-403.

4. Noegroho, Harum Sasanti. Hubungan higiene mulut dan keparahan efek samping kronis akibat radioterapi kanker nasofaring (Disertasi). Jakarta: Fakultas Kedokteran Gigi Universitas Indonesia; 2004. p.18.

5. Wei WI, Sham JST. Nasopharyngeal carcinoma. Lancet. 2005;365:2041-54.

6. Spano JP, Busson P, Atlan D, Bourhis J, Pignon JP, et al. Nasopharyngeal carcinomas: an update. Eur J Cancer. 2003;39:2121-35.

7. Lee AWM, Foo W, Law SCK, Poon YF, Sze WM, et al. Nasopharyngeal carcinoma - presenting symptoms and duration before diagnosis. HKMJ. 1997;3:355-61.

8. Union for International Cancer Control. TNM Classification of Malignant Tumours, 7th ed. 2009.

9. Reiter S, Gavish A, Winocur E, Emodi-Perlman A, Eli I. Nasopharyngeal carcinoma mimicking a temporomandibular disorder: a case report. J Orofac Pain. 2006;20:74-81.

10. Khan J, Quek SYP, Markman S. Nasopharyngeal carcinoma masquerading as TMJ orofacial pain. Quintessence Int. 2010; 41:387-9.

11. Okeson, Jeffrey P. Management of temporomandibular disorders and occlusion, 7th ed. St. Louis: Elsevier. 2013. p.232

12. Chan JKC, Bray F, McCarron P, Foo W, Lee AWM, et al. Nasopharyngeal carcinoma. In: Barnes L, Eveson JW, Reichart P, Sidransky D, editors. World Health Organization Classification of Tumors: Pathology and Genetics of Head and Neck Tumors. Lyon: IARC Press. 2005. p.85-97.

13. Atkinson ME, White FH. Principles of anatomy and oral anatomy for dental students, 1 st ed. London: Churchill Livingstone. 1992. p.334

14. Barasch A, Cunha-Cruz J, Curro FA, Hujoel P, Sung AH, et al. Risk factors for osteonecrosis of the jaws: a case-control study from the CONDOR Dental PBRN. J Dent Res. 2011;90:439-44.

15. Khosla S, Burr D, Cauley J, Dempster DW, Ebeling $\mathrm{PR}$, et al. Biphosphonate-associated osteonecrosis of the jaw: report of a task force of the American
Society for Bone and Mineral Research. J Bone Miner Res. 2007;22:1479-91.

16. Van Poznak C. Making a case for defining osteonecrosis of the jaw. J Dent Res. 2011;90: 399-401.

17. Wong JK, Wood RE, McLean M. Conservative management of osteoradionecrosis. Oral Surg Oral Med Oral Pathol Oral Radiol Endod. 1997;84:1621.

18. Glastonbury CM, Parker EE, Hoang JK. The postradiation neck: evaluating response to treatment and recognizing complications. Am J Roentgenol. 2010;195:W164-71.

19. $\mathrm{Hu}$ WW, Ward BB, Wang Z, Krebsbach PH. Bone regeneration in defects compromised by radiotherapy. J Dent Res. 2010; 89:77-81.

20. Lye KW, Wee J, Gao F, Neo PSH, Soong YL, Poon CY. The effect of prior radiation therapy for treatment of nasopharyngeal cancer on wound healing following extractions: incidence of complications and risk factors. Int J Oral Maxillofac Surg. 2007;36:315-20.

21. Fang FM, Leung SW, Wang CJ, Su CY, Lui CC, et al. Computed tomography findings of bony regeneration after radiotherapy for nasopharyngeal carcinoma with skull base destruction: implications for local control. Int J Radiat Oncol Biol Phys. 1999;44:305-9.

22. Lypka MA, Urata MM. Cocaine-induced palatal perforation. N Engl J Med. 2007;357:19.

23. Patel V, Mahajan S, Kharkar V, Khopkar U. Nasal extranodal NK/T-Cell lymphoma presenting as a perforating palatal ulcer: a diagnostic challenge. Indian J Dermatol Venereol Leprol. 2006;72:21821.

24. Sharma R, Sirohi D, Sinha R, Menon PS. Palatal perforation secondary to tuberculosis: a case report. J Maxillofac Oral Surg. 2013; 12:326-8.

25. Houston GD, Brown FH. Differential diagnosis of the palatal mass. Compendium. 1993;14:1222-4.

26. Marsh P, Martin MV. Oral Microbiology, 4th ed. Oxford: Wright. 1999. p.1-4, 17.

27. Aas J, Paster BJ, Stokes LN, Olsen I, Dewhirst FE. Defining the normal bacterial flora of the oral cavity. J Clin Microb. 2005; 43:5721-32.

28. Field EA, Allan RB. Review article: oral ulceration - aetiopathogenesis, clinical diagnosis and management in the gastrointestinal clinic. Aliment Pharmacol Ther. 2003;18:949-62.

29. Van Heerden WFP, Boy SC. Diagnosis and management of common non-viral oral ulcerations. SA Fam Pract. 2007;49:20-6.

30. Vissink A, Jansma J, Spijkervet FKL, Burlage FR, Coppes RP. Oral sequelae of head and neck radiotherapy. Crit Rev Oral Biol Med. 2003;14:199212.

31. Rapoport AP, Miller Watelet LF, Linder T, Eberly $\mathrm{S}$, Raubertas RF, et al. Analysis of factors that correlate with mucositis in recipients of autologous 
and allogeneic stem-cell transplants. J Clin Oncol. 1999; 17:2446-53.

32. Lalla RV, Sonis ST, Peterson DE. Management of oral mucositis in patients with cancer. Dent Clin North Am. 2008;52:61-8.

33. Jones CG. Chlorhexidine: is it still the gold standard? Periodontol. 2000; 1997;15:55-62.

34. Shieh SH, Wang ST, Tsai ST, Tseng CC. Mouth care for nasopharyngeal cancer patients undergoing radiotherapy. Oral Oncol. 1997;33:36-41.

35. Barasch A, Elad S, Altman A, Damato K, Epstein J. Antimicrobials, mucosal coating agents anesthetics, analgesics, and nutritional supplements for alimentary tract mucositis. Support Care Cancer. 2006;14:528-32.

36. Broadfield L, Hamilton J. Best practice guidelines for the management of oral complications from cancer therapy. Supportive Care Cancer Site Team, Cancer Care Nova Scotia, 2006. p.4,7,32-6,57.

37. Sufiawati I, Subita GP. Identifikasi dan pengendalian faktor risiko mukositis oral selama radioterapi kanker nasofaring. J Dent Indones. 2008;15:155-62.

(Received June 29; 2014, Accepted July 24, 2015) 